\title{
Development of a predictive model for growth of Listeria monocytogenes on cooked sausage in cold storage in the household
}

\author{
Ye-Jin Han, Myoung-Su Park, Gyung-Jin Bahk* \\ Department of Food and Nutrition, Kunsan National University, Gunsan 54150, Korea
}

\section{가정에서 냉장보관 중인 소시지에서의 Listeria monocytogenes에 대한 성장 예측 모델 개발}

\author{
한예진 · 박명수 · 박경진 ${ }^{*}$ \\ 군산대학교 식품영양학과
}

\begin{abstract}
In household food safety management, it has been realized that the control of cooling storage temperature is crucial, particularly, for unpacked products. Therefore, we developed and tested a prediction model for the growth of Listeria monocytogenes in refrigerated cooked sausage in the household after unpacking. We studied the growth of $L$. monocytogenes as a function of temperature $\left(0,5,10\right.$, and $\left.15^{\circ} \mathrm{C}\right)$ and storage time $(0,1,2,3,5,7,10,12$, and 15 days). The results revealed that the Baranyi model was a suitable predictive model for determining $L$. monocytogenes growth. The Baranyi model was found to be highly accurate, as the experimentally determined $R^{2}(0.9991)$, root mean squared error (RMSE, 0.0563$)$, accuracy factor $\left(A_{f}, 1.0125\right)$, and bias factor $\left(B_{f}, 0.9997\right)$ could be approximated from the primary model. Further, based on the primary model, we developed a secondary polynomial model, which could predict the parameters lag time $\left(L T, R^{2}=0.9597\right)$ and maximum specific growth rate $\left(S G R, R^{2}=0.9465\right)$ with high accuracy. Thus, the Baranyi model can be successfully used to generate input variables in exposure assessment for conducting quantitative microbial risk assessment (QMRA) for $L$. monocytogenes in refrigerated cooked sausage in the household after unpacking.
\end{abstract}

Key words : Listeria monocytogenes, predictive growth model, cooked sausage, Baranyi model, food safety

\section{서 론}

식품의 안전을 보장하기 위해서는 적절한 저장 온도와 시간 관리가 가장 중요하다. 특히 적절한 냉장온도가 유지 되어야 하는 냉장 식품이 부적절한 온도로 유통될 경우 식중독 사고로 이어질 수 있으며 특히 유통의 마지막 단계 인 소비단계에서 적절한 온도관리가 이루어져야 한다. 하 지만 한국의 냉장고 온도 조사보고서에 따르면 평균 냉장 온도는 $3.53 \pm 2.96^{\circ} \mathrm{C}$ 이었으나 그 중 $23.65 \%$ 가 냉장온도인

*Corresponding author. E-mail : bahk@kunsan.ac.kr Phone : 82-63-469-4640, Fax : 82-63-466-2085

Received 07 December 2018; Revised 14 January 2019; Accepted 13 February 2019.

Copyright (c) The Korean Society of Food Preservation. All rights reserved.
$5{ }^{\circ} \mathrm{C}$ 보다 높았다고 보고되었다(1). 특히, 전 세계 가정의 $30 \%$ 는 권장되는 저장온도인 $5{ }^{\circ} \mathrm{C}$ 보다 높았으며(2-3), 가정 에서 냉장 보관된 식품 중 $6 \%$ 에서 Listeria monocytogenes가 검출되었다고 보고되었다(4).

L. monocytogenes의 최적 성장 온도는 $37^{\circ} \mathrm{C}$ 이며 성장 가 능한 온도 범위는 $-0.4-45^{\circ} \mathrm{C}$ 로, 냉장온도에서도 성장할 수 있기 때문에 cold chain system이 발달한 선진국에서도 발생 할 수 있는 식중독 균이며 특히 냉장식품들의 안전을 위협 하는 중요한 미생물학적 위해요소이다(5). 식품의 안전 관 리 측면에서 식품의 포장을 개봉한 후에는 균이 더 빠르게 성장하기 때문에 저온에서 보관하는 것이 권장되지만 $L$ monocytogenes의 경우 저온에서도 생존 및 성장할 수 있어, 특히 가정에서 동물성 식품을 부적절한 온도로 보관할 경우 리스테리아증의 원인으로 그 위험성이 두드러지게 지적 받고 있다(6) 
동물성 식품 중 하나인 소시지는 운송 및 판매 그리고 가정에서도 반드시 저온에서 보관되어야 하는 냉장식품이 며, Park 등(7)의 연구에 따르면 소시지는 평균적으로 한 달에 1회 이상 섭취하고 1 회 섭취 시 약 $64.59 \mathrm{~g}(107.65 \%)$ 을 섭취하여 한 명의 사람이 1 년에 약 $1.28 \mathrm{~kg}$ 을 소비한다고 보고되었다. 가정에서 소시지나 햄을 섭취할 때는 한 번에 다 섭취하기도 하지만 먹을 만큼만 이용한 뒤에 다시 보관 하는 경우가 빈번하며 이런 경우 부적절한 온도나 병원성균 등 다양한 위해에 노출될 수 있다. McMeekin(8)은 소시지의 모니터링을 통해 예측 모델과 용량-반응 모델을 적용한 위 해평가 결과 생산완료 시점에서 소시지의 L monocytogenes 의 초기 오염 수준은 최소 $4.0 \times 10^{2} \mathrm{CFU} / \mathrm{g}$ 이며 평균 $4.3 \times 10^{2}$ $\mathrm{CFU} / \mathrm{g}$, 최대 $8.1 \times 10 \mathrm{CFU} / \mathrm{g}$ 이었다고 보고하였다.

정량적 미생물 위해평가(quantitative microbial risk assessment, QMRA)는 미생물의 위험을 평가하는데 과학적 기반으로 한 구조화된 접근법을 통하여 수행되어야 하고(9), 소비단 계에서 $\mathrm{QMRA}$ 를 통해 식중독 사고 예방을 위한 적절한 안전관리방안을 세워야 한다. 성장예측모델은 $\mathrm{QMRA}$ 를 개 발하기 위한 노출평가의 한 부분으로 미생물의 성장을 평가 하기 위해서 사용되며(10), 이러한 성장예측모델은 특정 식품의 환경에 대해 수학적 모델을 사용하여 미생물의 성장 과 사멸과 같은 균의 변동 상태를 예측하고(11), 특정한 조건에서 식품의 안전을 보장하기 위해 적절한 예방 조치 (e.g. 온도 조절)를 찾는데 사용된다(12). 따라서 본 연구에 서는 가정에서 개봉 후 냉장보관 중인 소시지에서 $L$. monocytogenes에 대한 식품의 안전성 보장과 QMRA 노출 평가에 활용할 수 있는 성장예측모델을 개발하고자 하였다.

\section{재료 및 방법}

\section{표준균주}

본 연구에서 사용된 표준균주는 Pal 등(13)이 worst-case scenario의 시뮬레이션 연구 시 성장의 여부를 분명하게 구분할 수 있도록 빠른 성장을 보인 L. monocytogenes ATCC 19115(serotype 4b)으로 농림축산검역본부에서 분양 받았으며, tryptic soy broth(TSB, Difco Laboratories, Detroit, $\mathrm{MI}, \mathrm{USA}$ )에 전 배양하여 $1 \mathrm{~mL}$ 를 vial tube에 $10 \%$ glycerol을 첨가하여 $-70^{\circ} \mathrm{C}$ 에 동결 보관하면서 사용하였다.

\footnotetext{
시험균액 제조

보관된 표준균주는 냉장온도에서 해동 후 $L$ monocytogenes 의 선택배지인 oxford listeria selective agar(Oxoid, Basingstoke, Hampshire, UK)에 streaking 하여 $35^{\circ} \mathrm{C}$ 에서 24 시간 동안 배양 후 전형적인 집락인 black halo를 나타내는 단일 집락의 균주를 취하여 사용하였다. 선택배지에서 분 리된 단일 집락의 $L$ monocytogenes를 $10 \mathrm{~mL}$ 의 $\mathrm{TSB}$ 에 접종
}

하여 $35^{\circ} \mathrm{C}$ 에서 24 시간 후 계대 배양한 후 최종적으로 약 $1.0 \times 10^{2} \mathrm{CFU} / \mathrm{mL}$ 수준으로 희석하여 이를 시험 균액으로 사용하였다.

\section{시료 준비 및 균액 접종}

본 연구에 사용한 소시지는 국내 소비자들에게 가장 인 기 있는 5 가지 소시지를 선택하여 군산시 대형마트에서 구매 후 아이스박스에 보관하며 시험장소로 30 분 이내 운 반한 뒤 실험 전까지 냉장온도 $4^{\circ} \mathrm{C}$ 에 보관하며 사용하였다. 소시지와 관련하여 $L$ monocytogenes의 성장과 관련된 중요 한 변수는 온도와 시간이 가장 중요한 요인이라고 보고(1) 하였기에, 냉장보관 중인 소시지의 포장지를 개봉한 후 멸 균된 가위로 종류별 소시지를 각각 절단하여 총 무게의 합이 약 $10 \pm 0.2 \mathrm{~g}$ 이 되도록 한 후 보관온도는 $0,5,10,15^{\circ} \mathrm{C}$, 보관시간은 $0,1,2,3,5,7,10,12,15$ 일로 하였다. 단, 소시지 와 같은 식육가공품에서 $L$ monocytogenes의 성장은 식품의 특성이나 첨가제 및 방부제에 따라 다르지만(14-15), 본 연구의 목적이 가정에서 개봉 후 냉장보관 시 $L$. monocytogenes 성장예측모델을 개발하는 것이므로 개별 소 시지 제품의 세부적인 사항(e.g. 첨가제, 방부제 등)은 배제 하였다. 절단된 소시지는 $1.0 \times 10^{2} \mathrm{CFU} / \mathrm{mL}$ 의 균액에 20 분 간 침지시킨 후 멸균백에 넣어 각 보관온도에 저장하면서 균수를 측정하였으며, 총 3 회 반복 실험하였다.

\section{성장 측정}

L. monocytogenes가 접종된 시료를 $0.1 \%$ peptone water로 10 배 희석한 뒤 stomacher로 1 분 동안 균질화한 후, easy Spiral ${ }^{\circledR}$ Plater(Interscience, Bretèche, France)를 사용하여 $L$. monocytogenes 선 택배지인 oxford listeria selective agar에 접종한 후 $30^{\circ} \mathrm{C}$ 에서 24-48시간 동안 배양하였다. 배양 결 과는 반복 실험의 결과를 통해 확인되었으며 $L$. monocytogenes의 전형적인 집락인 black halo가 형성된 집 락만을 계수하여 각 조건의 평균값을 $\log \mathrm{CFU} / \mathrm{g}$ 으로 계산 하였다.

\section{성장예측모델 개발 및 적합성 평가}

1차 모델은 Baranyi 모델식(16)과 DMFit(Institute of Food research, Norwich, UK, http://www.ifr.ac.uk/safety/dmfit/) 프 로그램을 사용하여 개발하였다(Table 1). 온도에 따른 성장 곡선을 바탕으로 curve fitting 하였으며, 1 차 모델의 growth parameters는 McKellar와 $\mathrm{Lu}(17)$ 가 기술한 방법을 참조하여 lag time(LT, $\lambda$ )과 maximum specific growth rate(SGR, ${ }_{\max }$ ) 을 산출하였다. Fitting을 통해 얻은 예측된 값과 실험한 값을 비교하여 $\mathrm{R}^{2}$ 및 root mean squared error(RMSE), accuracy factor $(A)$, bias factor $(B)$ 을 계산하여 모델의 적합 성을 평가하였다. 
Table 1. Primary growth models used to predict growth of $L$. monocytogenes in refrigerated cooked sausage after the packaging had been opened in household

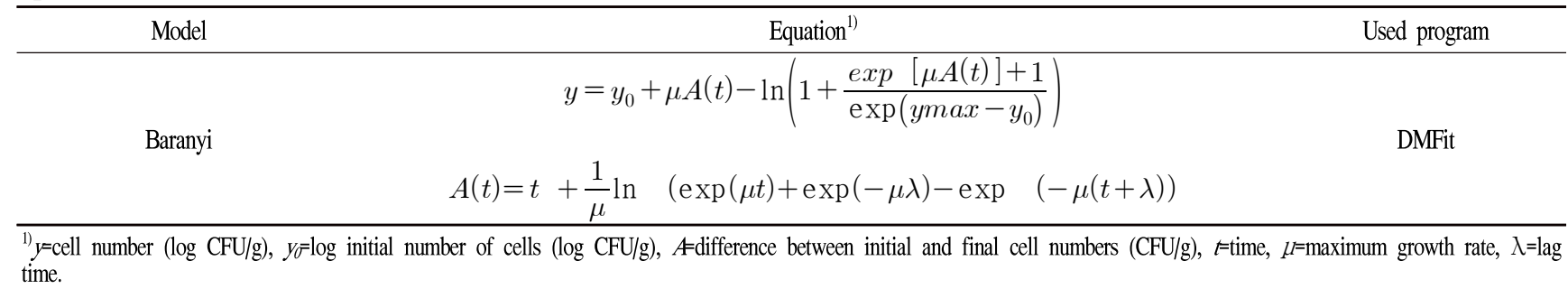

$$
\left[R^{2}=1-\left(\sum \frac{e_{i}^{2}}{\sum\left(y_{i}-\hat{y}\right)}\right)^{2}\right]
$$

$e i$ : the error of predictive data

yi : the predictive data

$\hat{y}:$ the average of predictive data

$$
\left[R M S E=\sqrt{\frac{\sum(\text { obs }- \text { pred })^{2}}{n}}\right]
$$

obs : observed value

pred : predicted value

$n$ : number of observations

$$
\left[A_{f}=10\left\{\frac{\sum\left|\log \left(\frac{\text { pred }}{\text { obs }}\right)\right|}{n}\right\}\right]
$$

obs : observed value

pred : predicted value

$n$ : number of observations

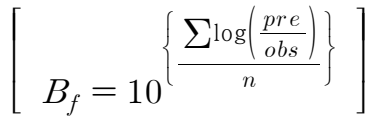

obs : observed value

pred : predicted value

$n$ : number of observations

1 차 모델 결과를 바탕으로 하여 2차 모델을 개발하기 위해 SigmaPlot(Ver 10.0, Systat Software, San Jose, CA, USA) 프로그램을 이용하여 온도에 대한 polynomial model을 개 발하였으며 2차 모델의 parameter인 온도와 시간에 따른 $\mathrm{LT}$ 와 $\mathrm{SGR}$ 의 정확성을 확인하였다.

\section{결과 및 고찰}

개봉한 소시지에 L. monocytogenes를 초기 접종 농도 2 $\log \mathrm{CFU} / \mathrm{g}$ 를 접종하여 15 일 동안 각 온도 및 시간 조건에서 실험한 결과, 보관온도 $0^{\circ} \mathrm{C}$ 및 $5^{\circ} \mathrm{C}$ 에서 보관 3 일이 될 때까 지 L monocytogenes는 성장하지 못하였으나, 5일 후부터는 $0^{\circ} \mathrm{C}$ 및 $5^{\circ} \mathrm{C}$ 에서 모두 성장하여 각각 최종 $4.12 \log \mathrm{CFU} / \mathrm{g}$, $5.66 \log \mathrm{CFU} / \mathrm{g}$ 까지 성장하였다(Fig. 1). Park 등(18)의 연구 에서는 L. monocytogenes의 최소 감염량을 일반적으로 $10^{2}-10^{3}$ cells $/ \mathrm{g}$ 으로 추정하였으며 보통 성인에게는 $7.8 \times 10^{7}$ cells $/ \mathrm{g}$ 수준으로 평가하였다. 본 연구에서는 $0^{\circ} \mathrm{C}$ 및 $5^{\circ} \mathrm{C}$ 에서 L. monocytogenes가 최종적으로 약 $4 \log \mathrm{CFU} / \mathrm{g}$ 이상으로 성장했기 때문에 정상적인 냉장온도에서 보관한다고 하더 라도 식품 섭취 대상자의 면역에 따라 충분히 식중독에 걸릴 가능성이 있다고 볼 수 있다. 또한 $10^{\circ} \mathrm{C}$ 및 $15^{\circ} \mathrm{C}$ 에서 저장하였을 때는 최대 $8.61 \log \mathrm{CFU} / \mathrm{g}$ 및 $8.64 \log \mathrm{CFU} / \mathrm{g}$ 까 지 성장하여 해당 온도에서 약 7일 보관 후에는 일반 성인에 게도 위험한 수준까지 성장하는 것으로 나타났다. 가공된 소시지의 경우 미생물의 성장을 저해하는 성분이 첨가되어 다른 식품과 직접적으로 비교할 수는 없지만, Lee 등(19)의 연구에서는 생돈육을 $5^{\circ} \mathrm{C}$ 에서 보관하였을 경우 최종 5.98

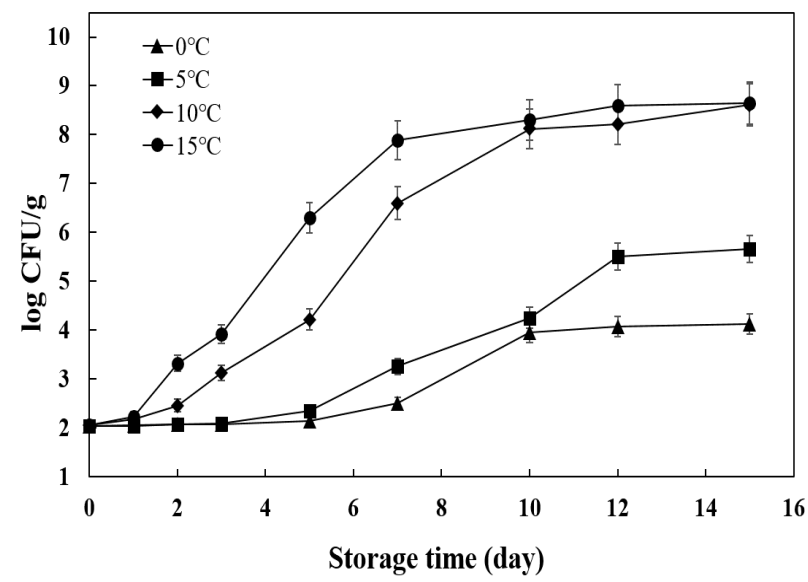

Fig. 1. The growth of $L$. monocytogenes in refrigerated cooked sausage after the packaging opened in household at different temperatures. 
$\log \mathrm{CFU} / \mathrm{g}, 15^{\circ} \mathrm{C}$ 에서는 $6.52 \log \mathrm{CFU} / \mathrm{g}$ 까지 성장하였으며, Cho 등(11)의 연구에서는 훈제연어를 대상으로 $4{ }^{\circ} \mathrm{C}$ 에서 $5.57 \log \mathrm{CFU} / \mathrm{g}, 10^{\circ} \mathrm{C}$ 에서 $7.58 \log \mathrm{CFU} / \mathrm{g}$ 까지 성장하여 본 연구와 유사한 결과를 보였다. 또한 Hong 등(20)의 냉장 돈육에 대한 연구에서는 $5^{\circ} \mathrm{C}$ 에서 5 일 만에 $5.36 \log \mathrm{CFU} / \mathrm{g}$ 까지 성장하였고, 더 높은 온도인 $10,15,20^{\circ} \mathrm{C}$ 에서는 이보다 빠르게 성장하여 본 연구보다 높은 성장률을 보였다.

일반적으로 식품에서 미생물 성장은 유도기, 지수기, 정 지기 및 사멸기의 단계를 거치며, 수학적으로 표현된 미생 물 성장에 대한 예측모델 개발시 사용되는 parameter로는 성장 단계별로 구분한 $\mathrm{LT}$ (유도기, lag time)와 SGR(최대성 장율, specific growth rate)이 주로 사용된다(5). 기타 parameter로는 정지기에서의 최대 성장수준(maximum growth value)을 사용할 수 있지만, 이는 발효과정 등에서 사용되며, 식품위생학적 측면에서는 주로 LT와 SGR만이 사용된다(10). LT는 유도기로 초기 단계로 미생물이 증식 하지 않고 성장을 위한 준비 시간 또는 온도 등 환경조건으 로 성장이 이루어지지 않는 시간을 나타내며, SGR은 유도 기 후 미생물 성장수준이 멈추는 정지기까지의 단계인 지수 기에서의 성장률을 나타낸다(16). 이러한 parameters들을 통해 식품의 내·외적인 요소(저장온도, $\mathrm{pH}, \mathrm{Aw}$ 등)에 따라
특정 미생물 성장수준이 어떻게 변화하는지를 예측할 수 있는 것이 수학적 성장예측모델이라고 정의하고 있다(20). 이에, 개봉한 소시지에서 L. monocytogenes에 대한 보관온 도 및 보관시간의 변화에 따른 성장 실험 결과를 바탕으로 한 1차 모델의 growth parameter는 Table 2와 같다. Baranyi 모델에서 산출한 $\mathrm{LT}(\mathrm{X})$ 는 $0,5,10,15^{\circ} \mathrm{C}$ 에서 각각 5.41 , $4.83,1.85,0.61$ 일로 온도가 증가할수록 감소하는 것으로 나타났다. Lee 등(19)의 연구에서는 Baranyi 모델을 통해 $5,15^{\circ} \mathrm{C}$ 에서 각각 약 $7.25,0.34$ 일로 측정되었고, Cho 등(11) 의 연구에서 사용한 Gompertz 모델은 $4,10^{\circ} \mathrm{C}$ 에서 각각 $10.7,4.6$ 일로 본 연구에 비해 성장을 시작하기까지 시간이 오래 걸렸다. 또한 $\mu_{\max }$ 는 $0,5,10,15^{\circ} \mathrm{C}$ 에서 각각 0.0177 , $0.0213,0.0349,0.0412$ 로 온도가 증가함에 따라 증가하였는 데, 이는 Codex(5), Lee 등(19), Hong 등(20)의 연구결과와 유사한 경향을 나타내었다. 결과적으로 개봉 후 냉장한 소 시지에서 L monocytogenes는 냉장온도에서 충분히 성장하 여 장시간 보관할 경우 식품안전에 위협이 되는 수준까지 성장하지만 저온에 비해 고온일수록 그 성장속도와 성장률 이 빠르게 증가하며 이런 점을 고려하였을 때 소비자의 식품의 보관온도와 보관시간 등 소비자의 행동과 위해 수준 에 영향을 미치며 가정에서 식품의 보관온도 관리가 중요할

Table 2. Estimated lag time ( $\lambda$, day), maximum specific growth rate ( $\mu_{\max }, \log$ CFU/g/day), $\mathrm{R}^{2}, \mathrm{RMSE}, B_{f}$ and $A_{f}$ of $L$. monocytogenes inoculated in refrigerated cooked sausage after the packaging had been opened in household using Baranyi model

\begin{tabular}{|c|c|c|c|c|c|c|}
\hline \multicolumn{7}{|c|}{ Baranyi model } \\
\hline \multirow{2}{*}{$\begin{array}{l}\text { Temp. } \\
\left({ }^{\circ} \mathrm{C}\right)\end{array}$} & \multicolumn{2}{|c|}{ Growth parameters } & \multicolumn{4}{|c|}{ Statistic evaluations } \\
\hline & $\lambda$ & $\mu_{\max }$ & $\mathrm{RMSE}^{1)}$ & $\mathrm{R}^{2}$ & $A_{f}^{2)}$ & $B_{f}^{3)}$ \\
\hline 0 & 5.4083 & 0.0177 & 0.0146 & 0.9997 & 1.0042 & 1.0000 \\
\hline 5 & 4.8258 & 0.0213 & 0.0123 & 0.9999 & 1.0040 & 0.9999 \\
\hline 10 & 1.84509 & 0.0349 & 0.0702 & 0.9993 & 1.0121 & 0.9996 \\
\hline 15 & 0.6120 & 0.0412 & 0.1280 & 0.9976 & 1.0298 & 0.9991 \\
\hline Mean & & & 0.0563 & 0.9991 & 1.0125 & 0.9997 \\
\hline
\end{tabular}

${ }^{1)}$ RMSE, root mean square error.

${ }^{2)} A_{\text {, accuracy factor. }}$

${ }^{3)} B_{f}$, bias factor.

Table 3. Coefficient of a second-order polynomial models used to predict the values of each parameter in Baranyi model as a function of temperature for $L$. monocytogenes inoculated in refrigerated cooked sausage after the packaging had been opened in household

\begin{tabular}{ccccc}
\hline Parameters & Variables & Coefficient & Second-order polynomial models & $\mathrm{R}^{2}$ \\
\hline $\mathrm{SGR}^{1)}$ & $y_{0}$ & 0.0168 & $=y_{0}+\mathrm{aX}{ }^{2)}+{ }_{\mathrm{b}} \mathrm{X}^{2}$ & 0.9597 \\
& $a$ & 0.0013 & & \\
& $b$ & $2.7810^{-5}$ & $=y_{0}+\mathrm{aX}+\mathrm{bX}^{2}$ & 0.9465 \\
& $y_{0}$ & 134.7725 & & \\
& $a$ & -5.9985 & -0.1559 & \\
& $\mathrm{LT}^{3)}$ & $b$ &
\end{tabular}

\footnotetext{
${ }^{1)} \mathrm{SGR}$, maximum specific growth rate $\left(\mu_{\max }\right)$

${ }^{2)} \mathrm{X}$, temperature $\left({ }^{\circ} \mathrm{C}\right)$.

${ }^{3}$ LT, lag time $(\lambda)$.
} 

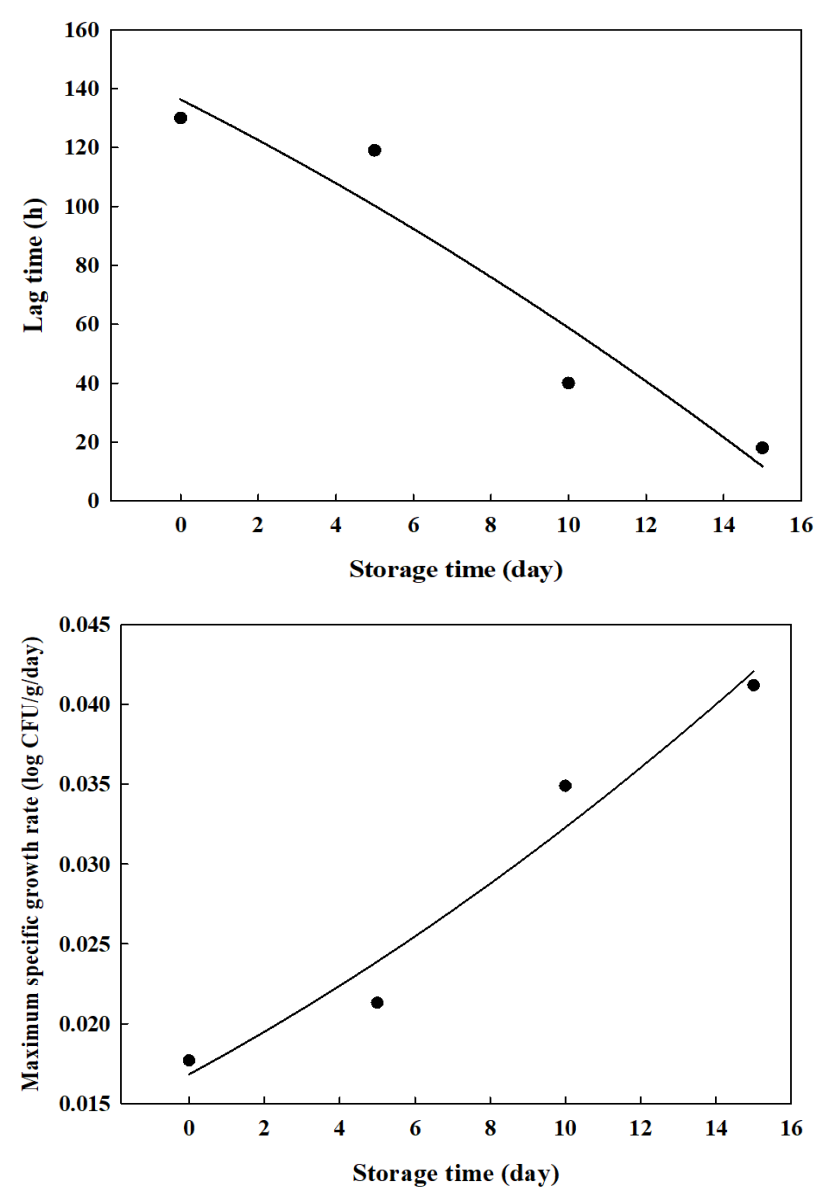

Fig. 2. Predicted secondary model to LT and SGR curve obtained from primary models.

것이다.

1 차 모델의 결과를 검증하기 위한 RMSE는 ' 0 '에 가까울 수록 $\mathrm{R}^{2}$ 는 ' 1 '에 가까울수록 fitting이 정확하다고 평가하며 Baranyi 모델을 이용하여 fitting한 결과와 실제 실험한 값을 비교하였을 때 각 온도에 따른 RMSE의 평균값은 0.0563 이 며 $\mathrm{R}^{2}$ 는 0.9991 로 정확도가 높게 측정되었으나 온도가 높아 질수록 정확성이 약간씩 감소하였다. $A_{f}$ 및 $B_{f}$ 또한 fitting하 여 예측된 값과 실험값의 정확성을 나타내는 척도이며 ' 1 ' 에 근접할수록 정확하다고 평가한다. 본 연구에서는 $A_{f}$ 와

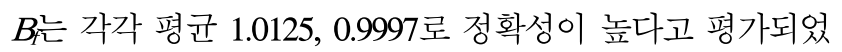
지만 온도가 올라갈수록 정확성이 감소하였으나, 저온에서 는 높은 정확성을 보였다. 또한, 1 차 모델의 parameter인 $\mathrm{LT}(\mathrm{\lambda})$ 와 SGR $\left(\mu_{\max }\right)$ 을 바탕으로 온도에 대하여 polynomial model(Fig. 2)을 개발하였으며 내부변수로 $\mathrm{y}_{0}$ 및 $\mathrm{a}, \mathrm{b}$ 를 사용 하였다(Table 3). 2 차 모델에서 SGR과 LT의 $\mathrm{R}^{2}$ 값은 각각 $0.9597,0.9465$ 로 높은 정확성을 보여 개봉 후 냉장온도에서 보관한 소시지의 L. monocytogenes에 대한 성장 예측 모델 로 사용 가능하다고 판단된다. 결과적으로 개봉된 소시지 는 저온에서 보관하더라도 L. monocytogenes는 성장할 수
있으며, 섭취하는 대상에 따라 최소 감염량은 다르지만 비 교적 낮은 수준에서도 감염될 수 있기 때문에 냉장온도인 $0-5^{\circ} \mathrm{C}$ 에서도 장시간 보관한다면 면역이 약한 사람에게는 위험할 수 있다(18). 또한 본 연구 결과, $10^{\circ} \mathrm{C}$ 및 $15^{\circ} \mathrm{C}$ 에서는 약 $8.6 \log \mathrm{CFU} / \mathrm{g}$ 까지 성장하였기 때문에 보통 성인에게도 위험한 수준으로 나타났다. 따라서 동물성 식품의 유통단 계와 개봉 후 보관할 때는 저온을 유지해 주는 것이 무엇보 다 중요하며 또 소비자의 빠른 소비가 동반되어야 할 것으 로 생각된다.

예측미생물학에서는 여러 가지 식품에서 가장 적합성이 높은 모델에 대한 다양한 의견이 존재한다(13). 본 연구에서 사용된 Baranyi 모델은 최근 주목을 받는 모델이며 본 연구 에서 높은 정확성을 보였다. 또한 Puerta-Gomez 등(6)과 Lee 등(19)의 연구에서도 Baranyi 모델이 modified Gompertz 모델과 Logistic 모델보다 더 우수한 fitting 결과 (RMSE, $B_{f} A_{f}$ 값이 각각 $0,1,1$ 에 더 근접하였음)를 나타냈 다고 보고하였다. 따라서 본 연구에서 개발된 가정에서 개 봉 후 냉장보관 중인 소시지에서 L. monocytogenes의 성장 예측모델은 향후 $\mathrm{QRMA}$ 노출평가 연구 결과의 정확성을 향상시키는데 기여할 수 있을 것으로 보인다.

\section{요 약}

식품안전관리 측면에서 일반 가정에서 포장된 식품을 개봉하였을 경우 흔히 저온저장을 해야 한다고 인식된다. 하지만 Listeria monocytogenes의 경우 냉장온도에서도 성 장이 가능하여 식품안전을 위협하는 식중독균으로 알려져 있다. 따라서 본 연구에서는 동물성 식품 중 하나인 소시지 를 대상으로 가정에서 개봉한 후 냉장온도에서 보관할 시 L. monocytogenes의 성장에 대한 예측 모델을 개발하였다. L. monocytogenes의 성장을 측정하기에 앞서 온도 $(0,5,10$, $\left.15^{\circ} \mathrm{C}\right)$ 및 시간 $(0,1,2,3,5,7,10,12,15$ 일 $)$ 을 설정하였으며 이러한 실험 결과를 기반으로 하여 L. monocytogenes의 성 장을 결정하기 위해 Baranyi model을 사용하였다. 일차모델 로서 Baranyi model의 적합성을 평가하기 위해 $\mathrm{R}^{2}$ 및 root mean squared error(RMSE), accuracy factor $\left(A_{f}\right)$, bias $\operatorname{factor}\left(B_{f}\right)$ 를 산출한 결과 각각 $0.9991,0.0563,1.0125,0.9997$ 로 높은 정확성을 보였다. 이러한 일차모델을 기반으로 하 여 이차모델인 polynomial model을 개발하였으며 매개변수 인 lag time(LT) 및 maximum specific growth rate(SGR)에서 $\mathrm{R}^{2}$ 는 각각 0.9597 및 0.9465 로 높은 정확성을 보였다. 따라 서 본 연구에서 개발된 가정에서 개봉 후 냉장보관 중인 소시지에서 L. monocytogenes의 성장예측모델은 향후 $\mathrm{QRMA}$ 노출평가 연구 결과의 정확성을 향상시키는데 기여 할 수 있을 것으로 보인다. 


\section{감사의 글}

이 논문은 2017년도 정부(미래창조과학부)의 재원으로 한국연구재단의 지원을 받아 수행된 연구(2017R1E1A1A 03070895)로서, 이에 감사드립니다.

\section{References}

1. Bahk GJ (2010) Statistical probability analysis of storage temperatures of domestic refrigerator as a risk factor of foodborne illness outbreak. Korean J Food Sci Technol, 42, 373-376

2. James SJ, Evans J, James C (2008) A review of the performance of domestic refrigerators. J Food Eng, 87, 2-10

3. Marklinder IM, Lindblad M, Eriksson LM, Finnson AM, Lindqvist R (2004) Home storage temperature and consumer handling of refrigerated foods in Sweden. J Food Prot, 67, 2570-2577

4. Kennedy J, Jackson V, Blair IS, McDowell DA, Cowan C, Bolton DJ (2005) Food safety knowledge of consumers and the microbiological and temperature status of their refrigerators. J Food Prot, 68, 142-1430

5. Codex Alimentarius Commission (2013) Principles and guidelines for the conduct of microbiological risk assessment (CAC/GL-30). Rome, Italy, p 1-6

6. Puerta-Gomez AF, Moreira RG, Kim J, Castell-Perez E (2013) Modeling the growth rates of Escherichia coli spp. and Salmonella Typhimurium LT2 in baby spinach leaves under slow cooling. Food Control, 29, 11-17

7. Park HJ, Go EK, Wee SH, Yoon H, Heo EJ, Kim YJ, Lee HS, Moon JS (2012) Analysis of foodborne pathogenic contamination of cooked hams and sausages in Korean processing facilities. Korean J Food Sci Ani Resour, 32, 103-111

8. McMeekin TA (2007) Predictive microbiology: Quantitative science delivering quantifiable benefits to the meat industry and other food industries. Meat Sci, 77, 17-27

9. Park JH, Cho JI, Joo IS, Heo JJ, Yoon KS (2016) Estimation of amount and frequency of consumption of 50 domestic livestock and processed livestock products. J Korean Soc Food Sci Nutr, 45, 1177-1191
10. Song BR (2012) The development of predictive model and estimation of growth for Listeria monocytogenes in mixed pressed ham and cooked sausage by storage temperature change. MS Thesis, Kunsan National University, Korea, p 24-44

11. Cho Jl, Lee SH, Lim JS, Kwak HS, Hwang IG (2011) Predictive mathematical model for the growth kinetics of Listeria monocytogenes on smoked salmon. J Food Hyg Saf, 26, 120-124

12. Godwin SL, Chen F, Chambers IV E, Coppings R, Chambers D (2007) A comprehensive evaluation of temperatures within home refrigerators. Food Prot Trends, 27, 168-173

13. Pal A, Labuza TP, Diez-Gonzalez F (2008) Comparison of primary predictive models to study the growth of Listeria monocytogenes at low temperatures in liquid cultures and selection of fastest growing ribotypes in meat and turkey products slurries. Food Microbiol, 25, 460-470

14. Hwang CA, Tamplin ML (2007) Modeling the lag phase and growth rate of Listeria monocytogenes in ground ham containing sodium lactate and sodium diacetate at various storage temperatures. J Food Sci, 72, M246-M253

15. Norwood DE, Gilmour A (2000) The growth and resistance to sodium hypochlorite of Listeria monocytogenes in a steady-state multispecies biofilm. J Appl Microbiol, 88, 512-520

16. Baranyi J, Roberts TA (1994) A dynamic approach to predicting bacterial growth in food. Int J Food Microbiol, 23, 277-294

17. McKellar RC, Lu X (2004) Modeling microbial responses in food. CRC press, Boca Raton, FL, USA, p 21-34

18. Park MS, Cho JI, Lee SH, Bahk GJ (2014) The analysis for minimum infective dose of foodborne disease pathogens by meta-analysis. J Food Hyg Saf, 29, 305-311

19. Lee YJ, Jung BS, Yoon HJ, Kim KT, Paik HD, Lee JY (2014) Predictive model for the growth kinetics of Listeria monocytogenes in raw pork meat as a function of temperature. Food Control, 44, 16-21

20. Hong CH, Sim WC, Chun SJ, Kim YS, Oh DH, Ha SD, Choi WS, Bahk GJ (2005) Predictive growth model of native isolated Listeria monocytogens on raw pork as a function of temperature and time. Korean J Food Sci Technol, 37, 850-855 